\title{
Representaciones de la Sociedad Colombiana a través de los anuncios publicitarios en los años cincuenta
}

Por: Jorge Hernán Rosero Pulido

Maestría en Historia, Universidad de los Andes.

El propósito de este trabajo es indagar el rol que desempeñaron los avisos publicitarios en la elaboración de representaciones, a partir de los discursos de venta y las imágenes, y de qué manera éstos contribuyeron en la construcción de un discurso modernizante en la sociedad colombiana de mediados del siglo XX. Además se propone rastrear en estos avisos qué hábitos de consumo proponían los anunciantes a los lectores de las revistas donde eran publicados los avisos.

Para este propósito realicé un rastreo de los avisos publicados en las revistas Semana, Cromos y Mito en el periodo comprendido entre 1951 y 1959, y construí un corpus de avisos publicitarios clasificándolos en avisos de productos industriales, avisos institucionales, avisos de entidades financieras y avisos de productos de consumo masivo. Una vez hecha esta selección tomé tres casos de estudio: Esso Colombiana, Censos Nacionales de 1951 y Laboratorios Squibb / Levadura Fleishmann los cuales analizaré en este trabajo. 


\section{Introducción: La sociedad colombiana en la década de los 50}

La década comprendida entre 1950 y 1959 fue una época en la cual la sociedad colombiana experimentó un acelerado proceso de modernización desde diferentes ámbitos; a nivel político Palacios y Safford (2002) ' ', señalan que el país vivió entre 1946 y 1957 bajo un régimen basado en los viejos principios del conservadurismo pero que convivía junto a grandes transformaciones económicas de tipo liberal; este orden se construyó sobre cuatro pilares:

- Valor estratégico acordado a la industrialización y al proteccionismo

- Control a los sindicatos y las bases obreras mediante una combinación de represión, paternalismo empresarial y catolicismo social

- Desmovilización electoral a la que contribuyó la abstención liberal en las elecciones entre 1949 y 1957.

- Alianzas con Estados Unidos para desarrollar la electrificación, ampliación de redes de transporte y comunicaciones.

Cabe señalar que el país estuvo en un permanente estado de excepción de 1949 a 1957, período en el cual las libertades estaban restringidas. Los dirigentes políticos de la época tenían la idea de que las movilizaciones políticas se podrían convertir en una amenaza para el sistema y poner en peligro el crecimiento económico. Esto se reflejaba en una censura que restringía la libertad de prensa.

En cuanto a los aspectos económicos, es preciso señalar, que en el periodo que continuó después del final de la Segunda Guerra Mundial se presentó un crecimiento económico importante en el país ${ }^{2}$. La industria se concentraba en Bogotá, Medellín, Cali y Barranquilla ${ }^{3}$.

1 Palacios, Marco, y Frank Safford. Colombia: país fragmentado, sociedad dividida. Bogotá: Norma, 2002 P 584.

${ }^{2}$ Para el periodo entre 1945 y 1955 el Producto Interno Bruto en Colombia creció a una tasa anual del $5 \%$ en promedio y la producción industrial creció al 9\% anual en promedio (Bushnell, 2007).
En aquella época se consolidaron los gremios como la ANDI, en el caso de los industriales, y FENALCO en el caso de los comerciantes; estos gremios estaban identificados, el primero, con el partido conservador y el segundo, con el partido liberal. Los gobiernos conservadores procuraron defender el principio de libertad de empresa e iniciativa privada.

En el campo de la cultura se puede observar un aparente contraste entre la limitación de libertades políticas y un florecimiento de la actividad cultural y artística; a pesar que los dirigentes conservadores señalaron que las políticas de democratización de la cultura implementadas en los gobiernos liberales fueron causantes directas de los problemas de orden público a partir de 1948. En consecuencia, durante la década de los 50 iniciaron una lucha contra toda modernidad educativa y cultural y un regreso a lo que denominaron "Raíces católicas e hispánicas de la nación" (Silva, 2015). Sin embargo, en la práctica, las dinámicas culturales iniciadas en los decenios anteriores a pesar de ser atacadas por los gobiernos conservadores continuaron su marcha.

Por último, también en los años 50 se dio inicio a espectáculos masivos deportivos como el Torneo Profesional de Fútbol y la Vuelta Ciclística a Colombia, estos dos deportes sirvieron como símbolos de integración nacional y construyeron los primeros héroes deportistas. La radio fue un factor fundamental para la difusión en una amplia escala de estos eventos.

Antes de iniciar el análisis de los avisos considero importante hacer un recorrido por los espacios donde se crearon y se imprimieron estos avisos publicitarios.

${ }^{3}$ Palacios (2002) hace un análisis interesante de las diferencias regionales entre los industriales de origen costeño y antioqueño asociándolos a un carácter más liberal, mientras que los industriales caleños tendían a tener un carácter más conservador. Esto generó fuertes rivalidades entre grupos de industriales y orientó las posiciones hacia un proteccionismo industrial. 


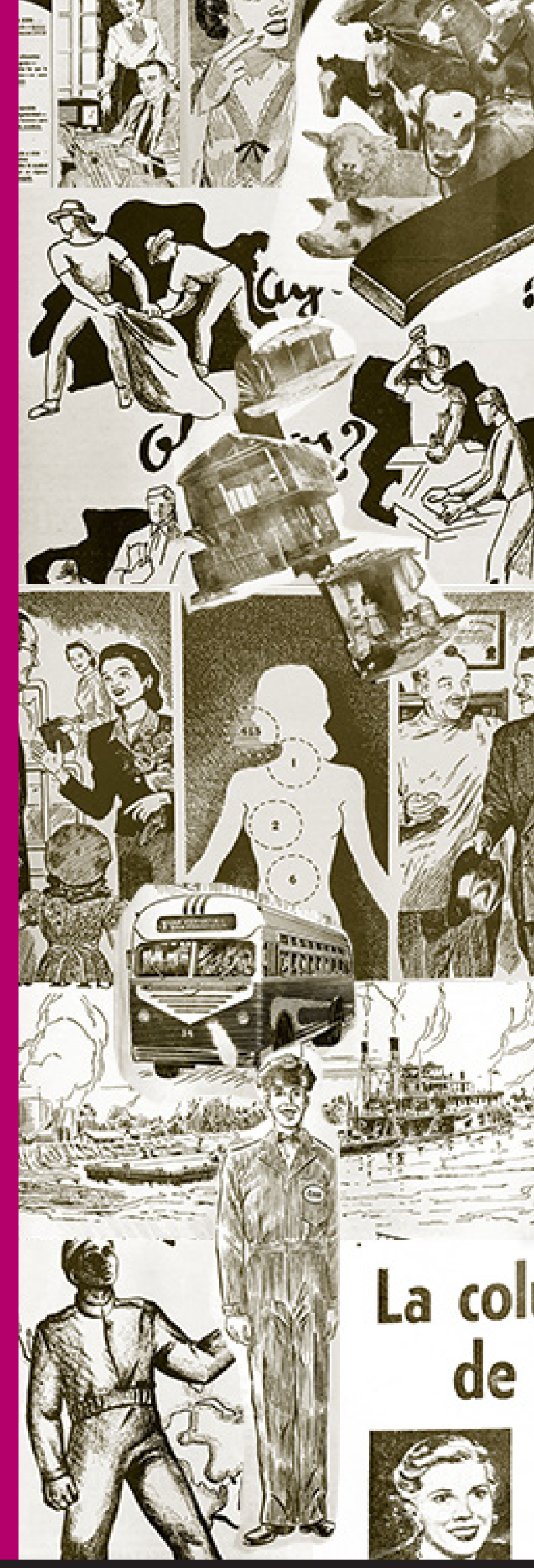

"Fue PROPAGANDA ÉPOCA la que implantó en Colombia los modernos sistemas del anuncio, creando los departamentos de planeamiento general, redacción especializada, radio, dibujo, investigaciones de ventas y mercados, consulta pública, relaciones públicas y dotando sus instalaciones de los instrumentos técnicos adecuados para cumplir la función que se había propuesto.

Para lograr esta finalidad importó especialistas de los Estados Unidos, Suiza, México, Chile y la Argentina y asimismo envió a jóvenes colombianos con aptitudes y aspiraciones a estudiar en el exterior los más modernos sistemas de propaganda"

En este sentido este proceso, además de presentarse un proceso de acumulación de capital económico; también se presentó una acumulación de capital simbólico en Bourdieu. Esto permitió que en los años 50 los nuevos profesionales en mercadeo y publicidad quienes vieron en este nuevo oficio una manera de adquirir prestigio social, vinculándose a una sociedad modernizada. 


\section{Las revistas como espacio de generación de representaciones}

La revista Cromos fue creada en 1916 como un semanario semanal ilustrado y se orientó a informar de manera visual los acontecimientos económicos, políticos y sociales, para los años 50 la revista ya estaba consolidada y aprovechó los adelantos en los sistemas de impresión para integrar en sus páginas recursos gráficos como las imágenes a color ${ }^{4}$.

En cuanto a la revista Semana, cuya primera edición circuló en 1946, siguiendo el modelo de las revistas norteamericanas de la época como Time y Newsweek ${ }^{5}$.

Mito fue una revista pionera en el ámbito cultural colombiano, circuló entre 1955 y 1962 contribuyendo a la divulgación de obras, tanto de autores colombianos como extranjeros, a un público que estaba acostumbrado a tener contacto con la literatura de manera esporádica por intermedio de los suplementos literarios de los periódicos capitalinos, El Tiempo y El Espectador.

A pesar de las limitaciones que imponía la censura de prensa que en la práctica operó en esta década se puede destacar que estas revistas, más que medios de transmisión de información, también fueron espacios de intercambio de ideas en el cuál redactores, ilustradores, publicistas, clientes y lectores construían un imaginario de una sociedad qué paso a paso de convertía en una sociedad moderna.

Los medios de comunicación, que para este análisis son las revistas, "son actores fundamentales en los procesos de conformación y manifestación de la opinión pública que se concretan en la conformación de comportamientos, actitudes y pensamientos en la sociedad ya sea para la toma de decisiones o en la elaboración de representaciones" 6. En este sentido, considero que no solo en la información de tipo editorial o noticioso se pueden generar estas representaciones, también los anunciantes con sus discursos e imágenes contribuyen a la elaboración, la consolidación o el cuestionamiento de tales representaciones.

Respecto de las representaciones, según Chartier son "las diferentes formas a través de las cuales las comunidades, partiendo de sus diferencias sociales y culturales, perciben y comprenden su sociedad y su propia historia"7

${ }^{6}$ Héctor Borrat, El periódico, actor político (Barcelona: Gustavo Gilli, 1989) ${ }^{7}$ Roger Chartier, El mundo como representación. Estudios sobre historia cultural (Barcelona: Gedisa, 2005). 


\section{Primer Caso de Estudio: Esso Colombiana:}

\section{Este es Nuestro PROBLEMA:}

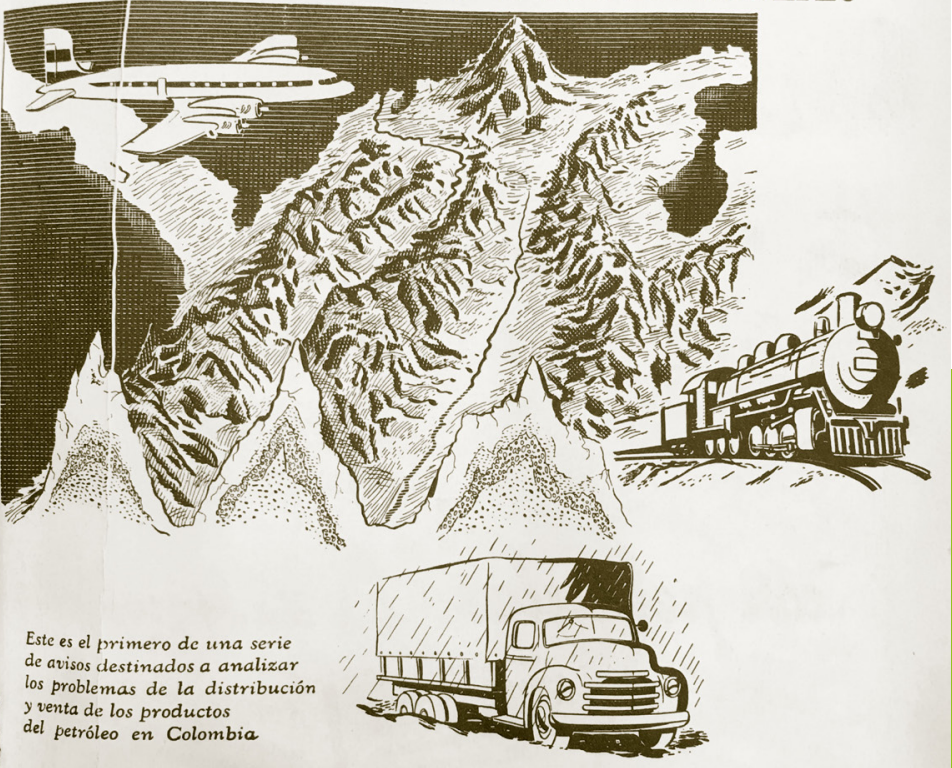

olombia es un país de abrupta y escarpada topografia. Tres elevadas cor dilleras lo atraviesan. eidena, los muy dificiles de vencer para los transportes.

A pesar de ello. Colombia crece y se desarrolla. Año tras año, dia tras dia, hemos visto trazarse kilómetros y kilómetros de carreteras, construirse las más atrevidas líneas férreas, elevarse los aviones por encima de las cordilleras. Todo esto impan Satisfacer esta creciente demanda es el problema que tiene que resolver prácticamente una sola compañia: la Esso Colombiana. Nadie tiene en Colombia monopolio para la distribución de los productos del petroleo. El mercado está abier to para tidad de abastecer a casi todo el pais, dentro de las limitaciones que pomponen el clima y la geografí.

\section{Esso Colombiana S.A.}

AVISO 1 Anunciante: Esso Colombiana S.A. Revista Semana, Bogotá, Volumen X, - Edición No. 226, febrero 17 de 1951

AVISO 2 Anunciante: Esso Colombiana S.A. Revista Semana, Bogotá, Volumen X - Edición No. 227, febrero 24 de 1951
Los inicios de la compañía en Colombia se remontan a inicios del siglo XX cuando la Tropical Oil Company se estableció en Barracabermeja realizando exploración petrolífera en los territorios entregados por el estado en el marco de la Consesión Mares. En los años cuarenta la Troco inicia una serie de compra de estaciones de servicio y termina cambiando su razón social a Esso Colombiana S.A.

La Esso publica en la revista Semana una serie de cuatro avisos, en febrero de 1951, que tienen como propósito que la empresa deje de ser vista como un monopolio, por parte de la opinión pública, en momentos en que está en marcha el proceso de reversión al Estado de la concesión de Mares. La intención de la Esso es la de presentarse ante la opinión pública como una empresa que, a pesar de actuar en un escenario de libre competencia, tienen, según ellos, la mayor responsabilidad en la distribución de derivados del petróleo en el país.

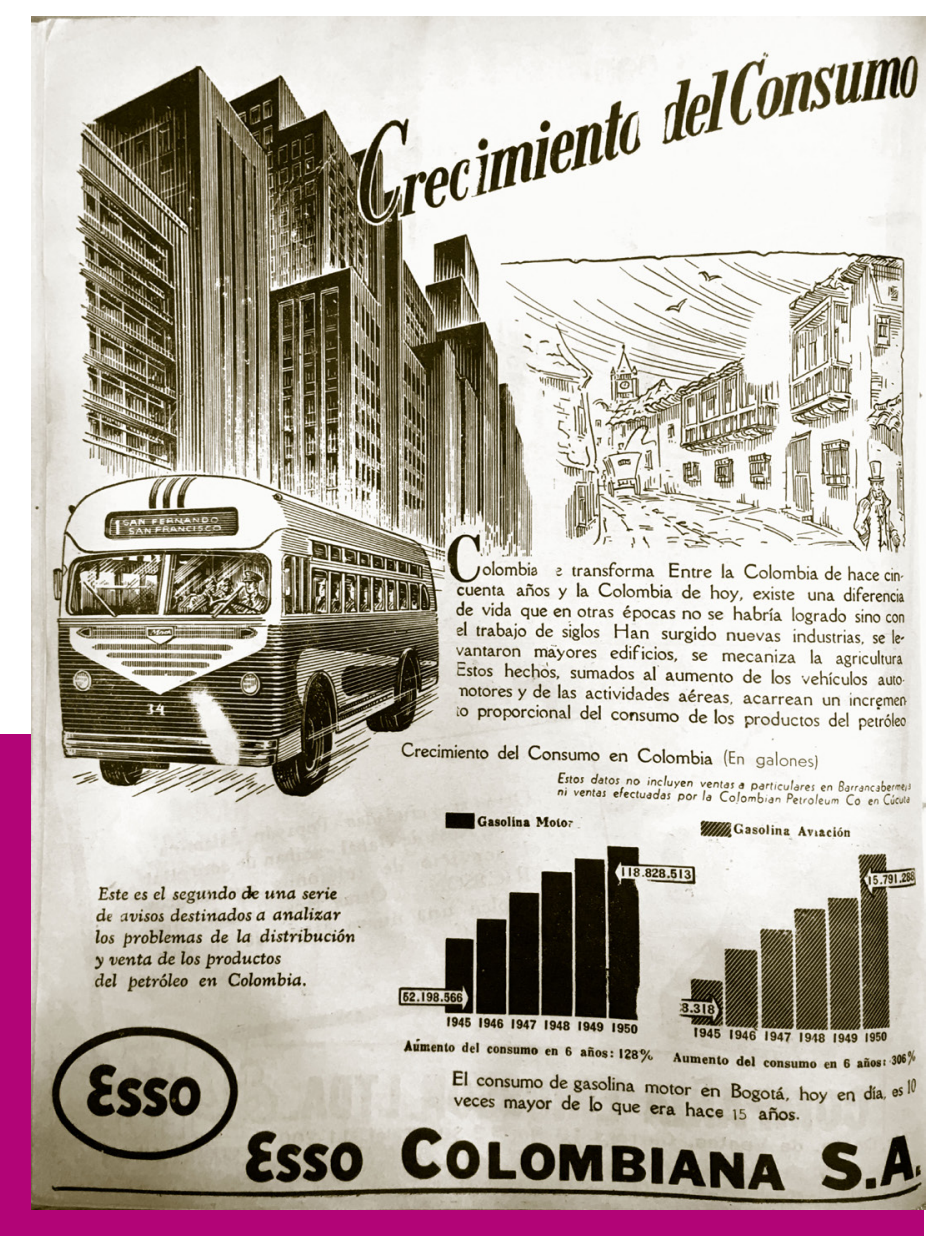


En el Aviso 1, parten del titular "Este es nuestro Problema", muestran un plano del país, exagerando la escala de las cordilleras para resaltar las dificultades topográficas que implica la distribución de los productos y se presentan como una compañía que está lista para atender la creciente demanda de gasolina.

En el Aviso 2 aborda de manera directa el crecimiento del consumo, señalando que el cambio producido en el país en los últimos cincuenta años ha sido mayor que en los anteriores siglos y que los procesos de industrialización, unidos al incremento del número de vehículos y aeronaves, han influido en el aumento del consumo de derivados del petróleo.

La ilustración que acompaña a este aviso es interesante por la manera como el dibujante plantea el contraste entre lo antiguo y lo nuevo, los edificios modernos ubicados en la izquierda del aviso enfrentados a la ciudad antigua que está al lado derecho. El dibujante hace uso de recursos técnicos como la perspectiva para que se perciba que los edificios modernos son más altos, mientras que en la ciudad antigua tiene una perspectiva diferente, el dibujo es más sencillo. Esta ilustración refuerza la idea de que lo nuevo es lo mejor y está asociada con el discurso modernista de la sociedad colombiana de mediados del siglo XX. En la ilustración subyace la idea de que las ciudades deberían transformarse y abrir espacio para los buses; esta misma idea se puede apreciar en la ilustración del Aviso 3 donde también entra en contraste la naturaleza selvática de las orillas del Río Magdalena con las instalaciones petroleras.

AVISO 3 Anunciante: Esso Colombiana S.A. Revista Semana, Bogotá, Volumen X - Edición No. 228, marzo 3 de 1951
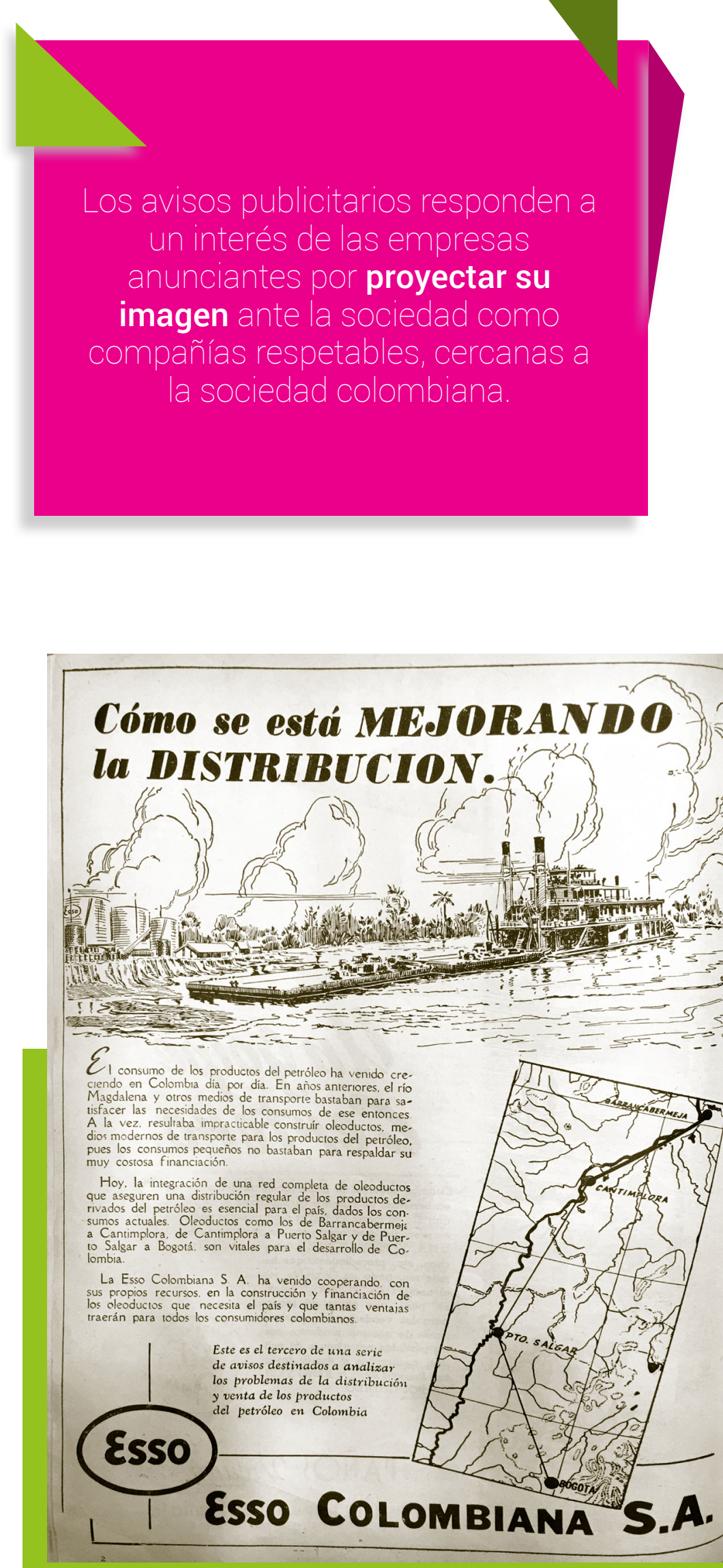


\section{Segundo Caso de Estudio: Censos Nacionales de 1951}

Éste fue el décimo segundo realizado en el territorio nacional. Su organización estuvo a cargo de la Dirección de la Estadística Nacional adscrita a la Contraloría General de la República y se realizó en conjunto con los Censos de Edificios y Viviendas, y el censo Agropecuario entre el 9 y el 31 de mayo de 1951. Cabe resaltar que la información estadística se planeó de acuerdo con las directrices emanadas del Comité de los Censos de América (COTA) con el fin de poder comparar la información estadística bajo unos parámetros uniformes.

AVISO 8 Anunciante: Contraloría General de la República. Revista Semana, Bogotá, Volumen X, edición No. 223, enero 27 de 1951

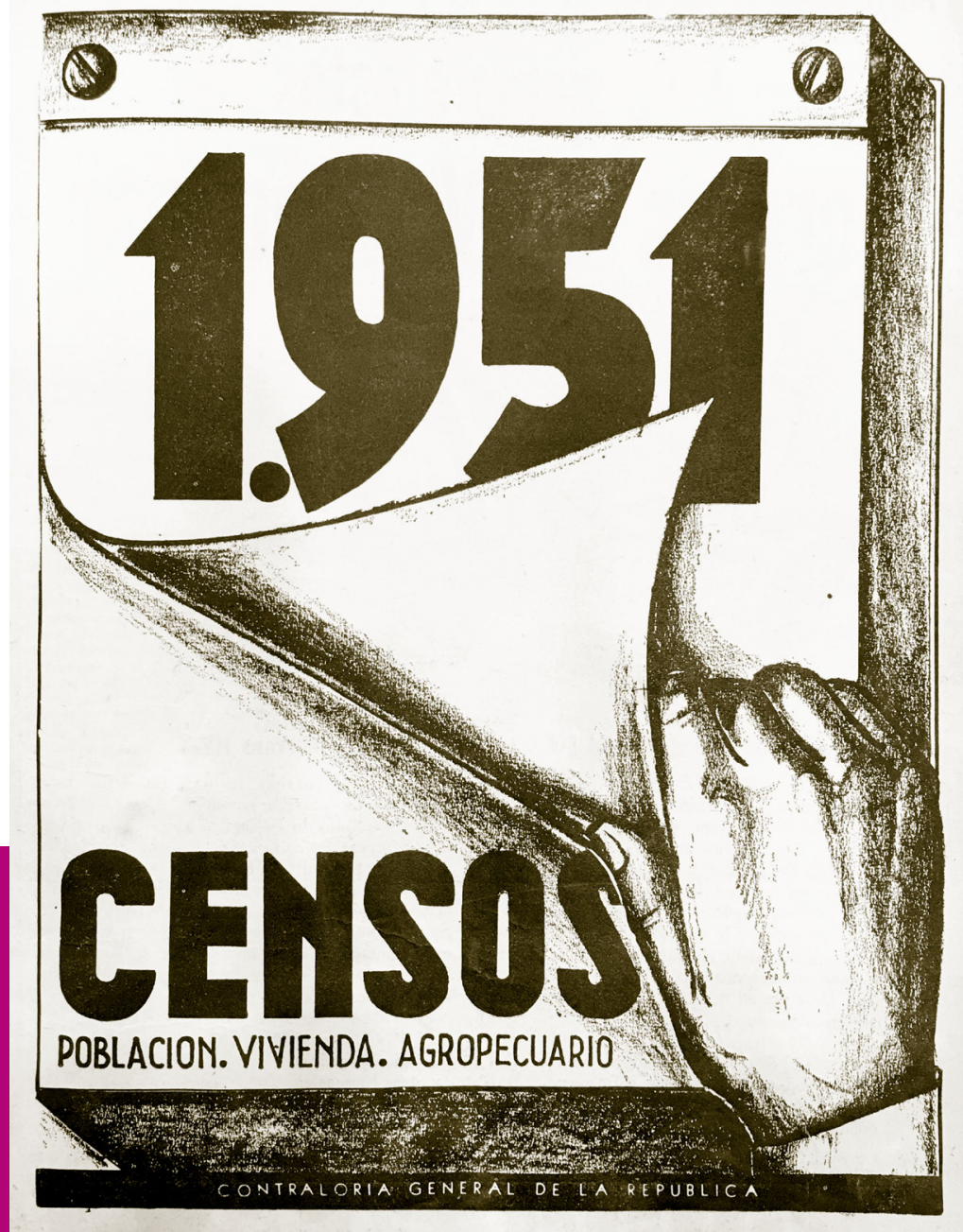

Los avisos que se analizaron corresponden a una campaña publicitaria (Definir) dirigida a diferentes actores participantes en el censo; empadronadores, ganaderos y la población en general, con el fin de movilizarlos y de esta manera contribuir a que la información del censo fuera lo más precisa posible.

El Aviso 8 invita a los lectores a tener en cuenta que durante el año se llevarán a cabo los censos nacionales, el uso del calendario hace referencia a la necesidad de no olvidar que se llevará a cabo este evento, consta de una única ilustración que representa el calendario de 1951, una mano pasa la hoja de portada para encontrar que en una próxima fecha se llevará a cabo la edición de los censos de población, vivienda y agropecuario. 


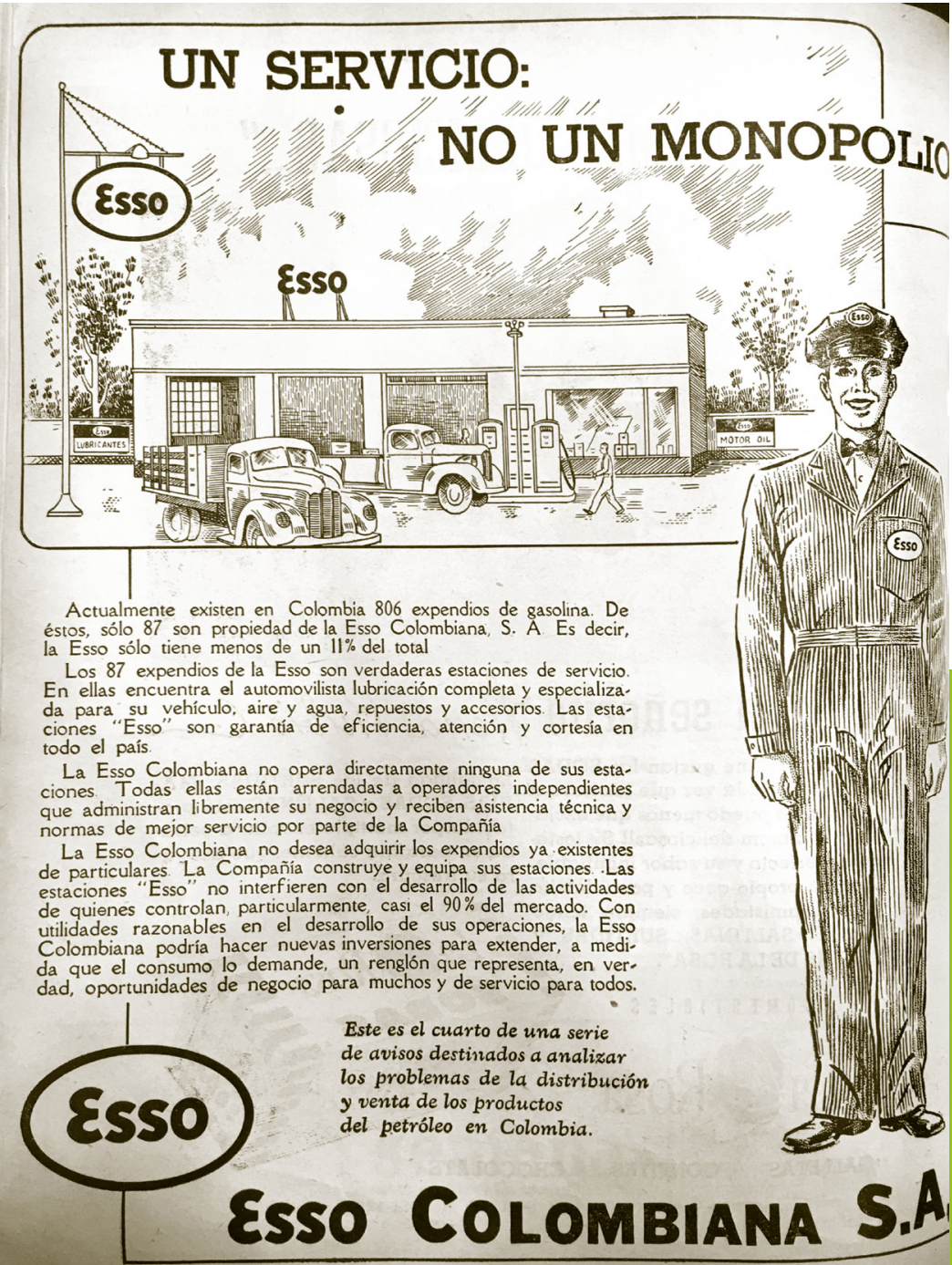

El Aviso 10 está dirigido a los empleados oficiales y los invita a presentarse a los delegados departamentales o al jefe de censos en los diferentes municipios del país para convertirse en empadronadores voluntarios. La invitación a convertirse en soldado alude al prestigio que tiene la figura, en aquellos momentos el Batallón Colombia está en Corea y ser soldado genera Prestigio. El soldado está en actitud victoriosa, clava una bandera en el mapa de Colombia, la cual está ubicada dentro del contexto continental. La bandera está marcada con el nombre de los censos.

AVISO 10 Contraloría General de la República. Revista Semana, Bogotá, Volumen X - Edición No. 234, abril 14 de 1951
El Aviso 9 pretende generar expectativa por los resultados del censo y que dichos datos contribuyan a mejorar las condiciones de vida de los colombianos. Hay una fe en la idea de progreso, de pensar que las cosas serán mejores. Al contrario del anterior aviso aquí se usa la fotografía como protagonista visual.

AVISO 9 Contraloría General de la República. Revista Semana, Bogotá, Volumen X - Edición No. 223, enero 27 de 1951

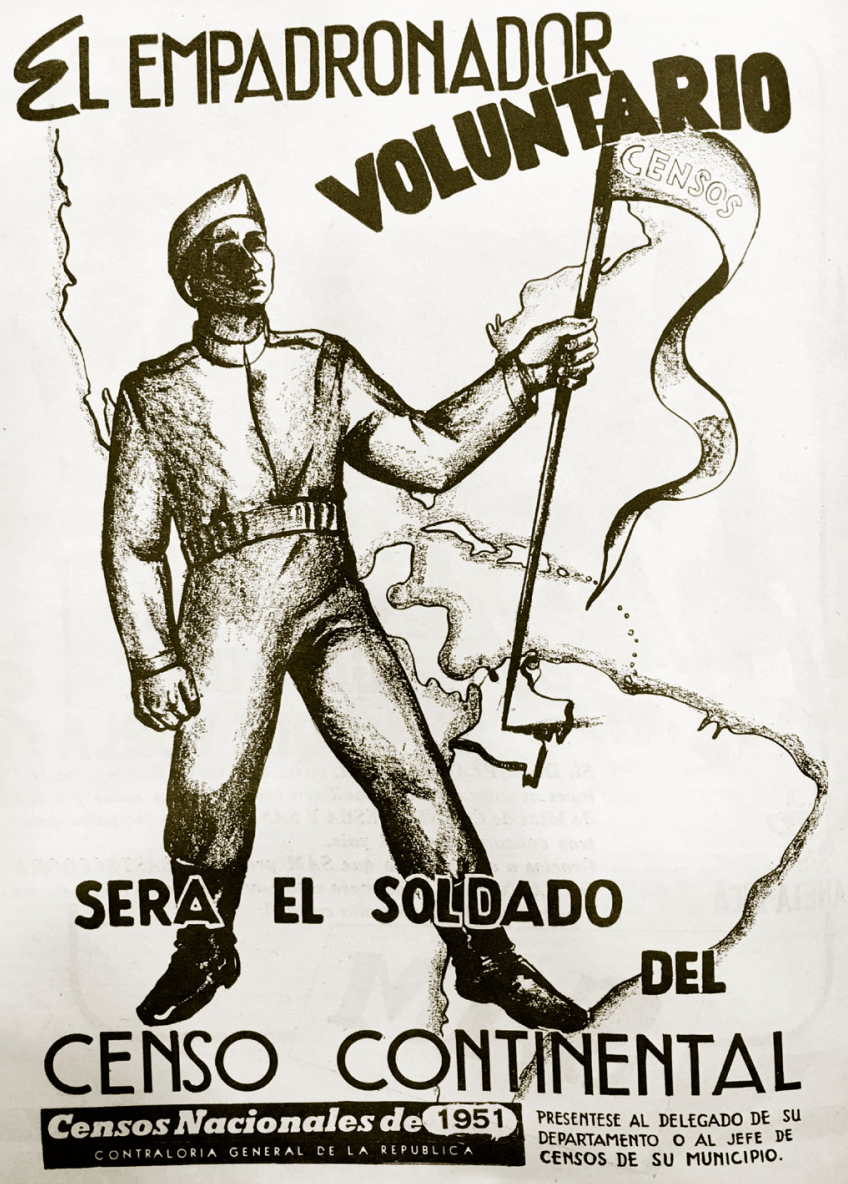




\section{GANADEROS:}

矿 EMADDROMADQResita

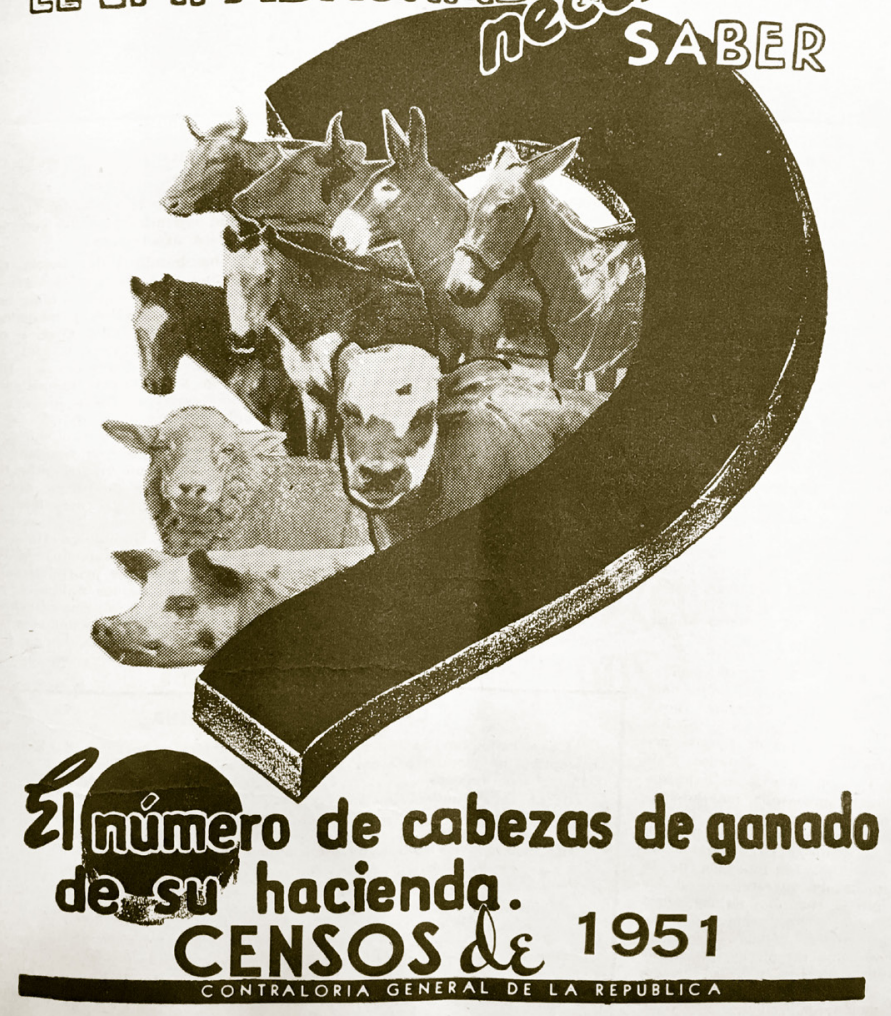

En el Aviso 12 el mensaje está dirigido al público en general y tiene el propósito de generar expectativa sobre cuáles serán las ocupaciones que son predominantes en la población colombiana. Las imágenes son sintéticas y representan a los agricultores, obreros y profesionales.

AVISO 12 Contraloría General de la República. Revista Semana, Bogotá, Volumen X - Edición No. 225, febrero 10 de 1951

El Aviso 11 está dirigido a los ganaderos con el propósito de que le suministren a los empadronadores la información que requieren para completar la información del ganado de sus haciendas. El tono del mensaje invita a los ganaderos a hacer parte del censo, a brindar toda la información referente al ganado de su hacienda. Se muestra un mosaico fotográfico de imágenes de ganado vacuno, ovino, equino y porcino con un gran signo de interrogación al lado derecho.

AVISO 11 Contraloría General de la República. Revista Semana, Bogotá, Volumen X - Edición No. 225, febrero 10 de 1951

\section{CUALES SON LAS OCUPACIONES PREDOMINANTES DE LA POBLACION} Colombiama?

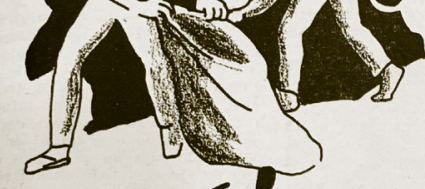

Greros?
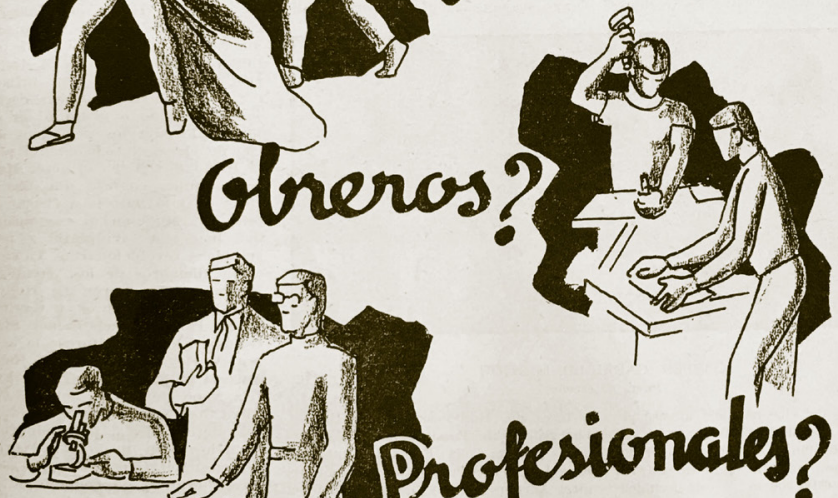
20

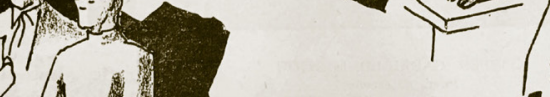

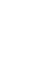


iUna dieta adecuada puede mejorar

SU APARIENCIA .. Y SU SALUd!

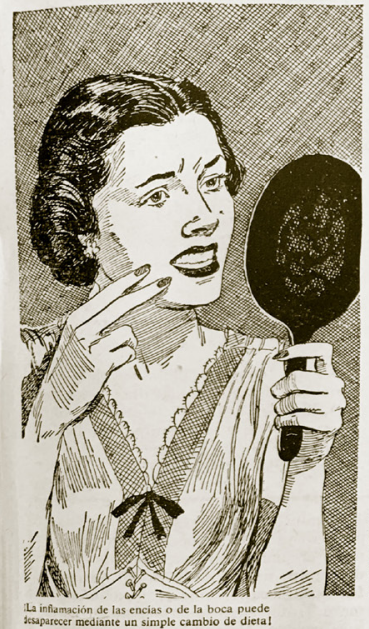

Cinco signos que pueden indicar la necesidad de un cambio de diefa: Agotamiento o palidez; fatigabilidad rápida 0 boca inflamadas. Estas son molestias muy
intala corrientes. A usted le pueden parecer sin importancia, pero no es así... Si observa alguna de ellas, vea a su médico. El puede a menudo hace desaparecer tales trastornos.

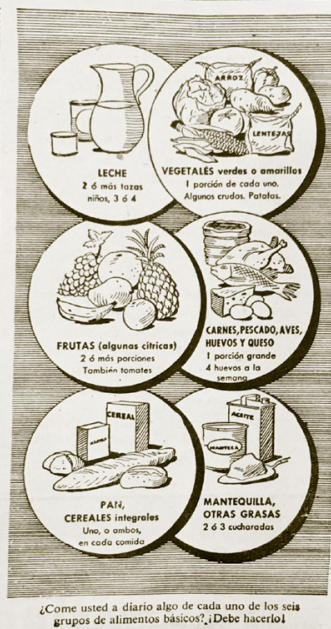

¡Guía para una diefa saludable! Arriba aparecen ilustrados los alimentos que usted debe ingerir diariamente para sentirse mejor tener mejor apariscia. Recorte esta guia... mentos básicos todos los días. Téngalos preentes al preparar sus comidas... su salud y a de su familia están en juego. Y recuerde: iNo hay un solo alimento que provea todos los factores nutritivos! Ud. y su fiavian

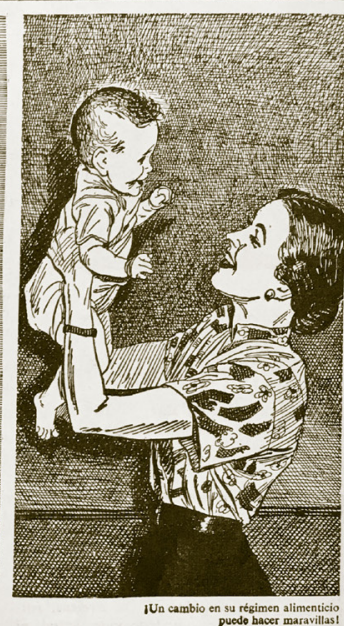

IGoce más de la vida! Si usted no ha seguido una dieta del todo adecuada, lo más de vitalidad si sigue fielmente la dieta equilibrada aconsejada por su médico. Por esto es sumamente importante no diferir un examen médico completo-sobre todo si usted se si-
ente muy cansado, nervioso, falto de energia. El médico puede informarle que usted nese rentemente más vitaminas y más $m$. nerales de los que su dieta actual contiene.

- Usted ve el nombre de Squibb en los estantes de su farmacia. Lo lee también muchas veces en las recelas de su médico. penicilina estreptos icina vitamines, anestésicos, hormon otras importantes especialidades medicinales. $Y$ es que desde 858 los Laboratorios de Investigación de Squibb han estado hallando, perfeccionando y produciendo medicinas, $y$ con-
tribuyendo asi a mjorar la salud $y$ aliviar el dolor humano.

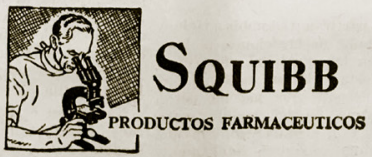

\section{iBuenas noticias sobre el Cáncer!}

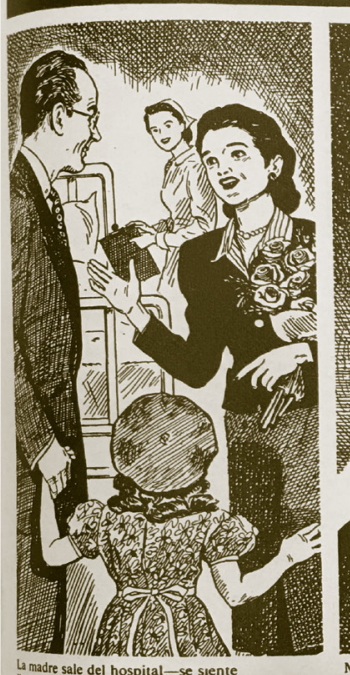

lamart sale del hospital-se sien
temand be bienstar y y ppimismo

ilo ciencio progresa comtra el cóncer!

Se ha adelantado mucho. Se experiment

wh hormonas, por ejemplo, con substa

Mis radioactivas, $y$ otras nuevas sub

Ancias quimicas con la esperanza de ha-

tribuido a stratamientos. Mucho ha con-

vicción a estel adelanto la creciente con-

de detenerse el desa de que en general pue-

descubre a el desarrollo del cáncer $s i$ se

Orma. Por suerte para todos, el cáncer

dos-a - mifiesta a menudo por signos defin:modo de advertencia.

- Usied ve el nombre de Squibb en los estantes de su farmacia. Lo lee también muchas veces en las recetas de su médico. quibb es uno de muchas veces en las recctas del mundo de penicilina, estreptomicis graites pros, anestésicos, hormona otras importantes especialidades medicinales. Y es que desd los Laboratorios de Investización de Squibb han estado uribuyen perfeccionando y produciendo medicinas, y con

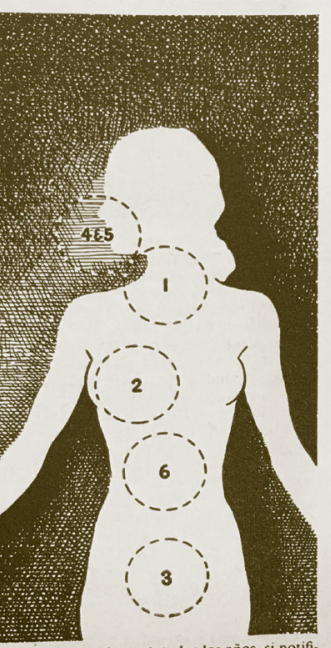

Miles dejarian de morir todos los años, si notifi-
caran la preseccla de esos sintomas a tiempo

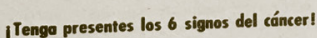

Tieng presentes los 6 signos del anicer

comuniquese con el médico en el acio!

Ronquera o tos-sin tener catarro Hemorragia irregular o creciente por cualCualquier ülcera que no cicatrice en un $\mathrm{mes}$

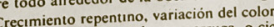
e la consistencia de un lunar, verruga, o ci 6. Ped persistente ca losi

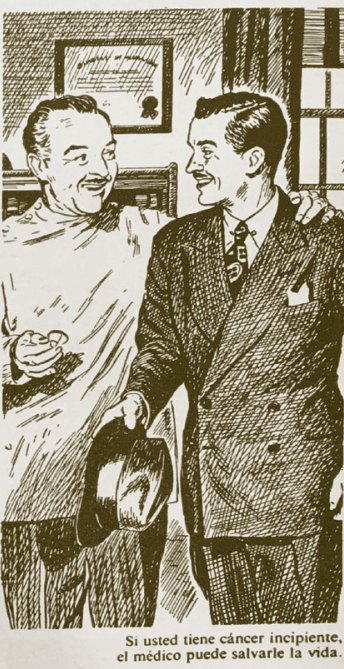

iEl cóncer incipiente puede ser detenido! Hoyen dia, gracias al diagnóstico precoz, se puede detener el cáncer en la mayoría de los casos. Usted no padece forzosamente de cáncer aun cuando tenga indicios de alguno de sus sintomas. mujeres que se sódico, 98 presentaron un diagnóstico negativo. Por tanto, no ema, investigue. El mayor peligro es la cardanza. Un examen a tiempo puede alvarle la vida. iEn caso de duda, consulte al médico inmediatamente?

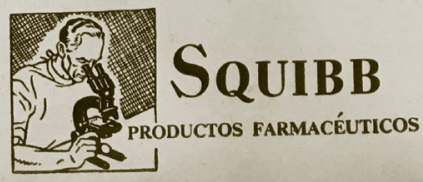

AVISO 14 Anunciante: E.R. Squibb \& Sons. Revista Semana, Bogotá, Volumen X-Edición No. 225, febrero 10 de 1951

En el Aviso 13 se invita a los lectores mayores de 40 años a hacerse tomar la presión sanguínea regularmente y a consultar al médico en caso de presentar algunos síntomas. En el discurso se hace énfasis en la necesidad de contar con el médico, seguir sus consejos y cooperar en el tratamiento de la enfermedad. Invita a quienes ya son hipertensos a vivir con calma a pesar de la hipertensión arterial.

En el Aviso 14 el anunciante presenta las ventajas de realizar una dieta saludable, al lado izquierdo presenta los síntomas de quienes no tienen una alimentación
AVISO 15 Anunciante: E.R. Squibb \& Sons. Revista Semana, Bogotá, Volumen X - Volumen X-Edición No. 231, marzo 24 de 1951

adecuada, en el centro presenta los grupos de alimentos y al lado derecho enfatiza en la necesidad de realizarse un exámen médico para recomendar una dieta equilibrada

En el Aviso 15 se aborda la problemática del cáncer señalando que la ciencia ha realizado progresos en su tratamiento, pero que el éxito depende de un diagnós tico precoz y nuevamente invita a consultar al médico de manera inmediata. 


\section{La columna vertebral}

de su dieta...

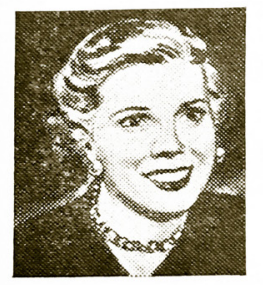

¿Reciben a diario los miembros de su familia las proténas necesarias para lograr el desarrollo normal del organismo?

\section{Por Laura Real}

Consejera de Nutrición de los fabricantes de Levadura Fleischmann
- Uno de los problemas de salud más extendidos, sea cual fure la situación

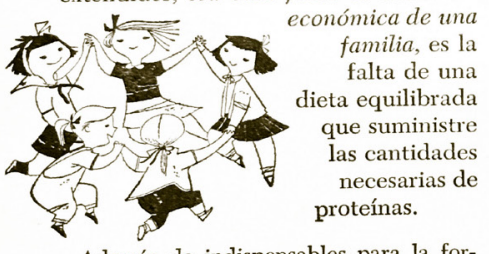

Además de indispensables para la formación y reparación de los tejidos del organismo, las proteínas producen hemoglobina, vital para la sangre. Las hormonas, fabricadas por las glándulas del cuerpo, y fabricadas por las glándulas del cuerpo, y las encimas, necesarias para ayudar de los alimentos, se producen a base de proteínas.

Las proteínas se encuentran en diversos alimentos, entre ellos el pan. Por eso el pan debe ser la base de toda alimentación equilibrada. Porque no hay fuente de energía alimenticia tan completa ni económica como el pan. Los niños en crecimiento gastan muchas energías y por ello deben consumir pan en abundancia, tanto para reponerlas como para formar un organismo sano. Insista Ud en que la dieta de su familia esté equilibrada, y que incluya leche, pan, queso y verduras.

Diversos estudios han demostrado que las proteínas en abundancia proporcionan bienestar a toda edad.
Si Ud. da a su familia las benéficas an proteinas que se necesitan a diario, verá como el aspecto de todos se torna más lozano y se sienten mejor tanto para trabajar como para gozar más de la vida.

\section{Aliméntese mejor... ICOMA MÁS PAN!}

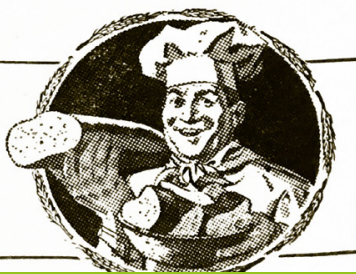

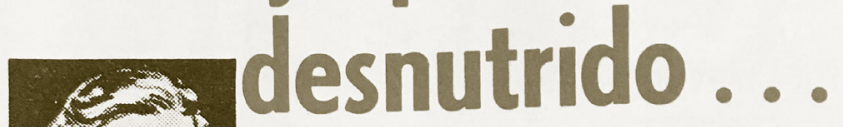

Un mensaje importante a las madres.

\section{Por Laura Real}

Consejera de Nutrición de los fabricantes de la Levadura Fleischmann

- ¿Está su hijo alicaído y falto de ener- miento. Cerciórese Ud. de que coma gía? ¡Cuidado con su dieta! No le deje una amplia variedad de alimentos todos comer alimentos "de relleno" que quizá los días.

carecen de suficientes vitaminas, mine- Para tener buena salud, su hijo nerales y otros factores nutritivos nece- cesita una ración diaria de cada uno de sarios para su salud, energía y creci- estos seis alimentos básicos:

Régimen alimenticio diario de un niño

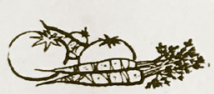
verdes $y$ amarillos abundan en vita. (ina A, necesaria para el desarrollo 14

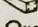

Leche, Queso, Mantequilia. La calcio. La leche y el queso constituyen una fuente de proteína; la crema $y$ b

Publicado por la Cía. Fleischmann Colombiana Inc.

como contribución al bienestar nacional
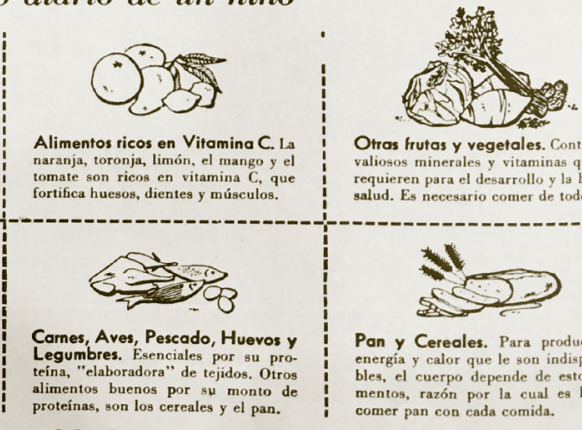

Otras frutas y vegetales. Contien Orras frutas y vegetales. Contienen
valiosos minerales y vitaminas que so
requieren para el desarrollo y la buen salud. Es necesario comer de todos.
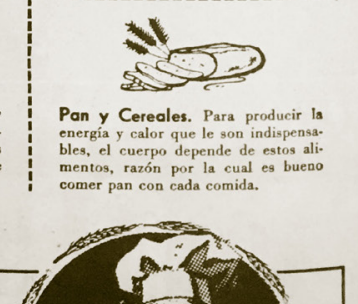

Aliméntese mejor... ¿COMA MÁS PAN!
AVISO 16 Anunciante: Levadura Fleischmann. Revista Cromos, Bogotá, Edición No. 2002, abril 4 de 1953

En cuanto a Fleischmann, es una compañía norteamericana dedicada a la comercialización de la Levadura, hongo que sirve como catalizador en el proceso de fermentación, el cual es esencial en la fabricación del pan. Esta empresa llegó a Colombia en 1930 y se ha dedicado a la elaboración, venta y distribución de ingredientes para panificación y pastelería.

Los avisos 16 y 17 que se analizarán a continuación, buscan incentivar el consumo de pan, presentándolo como "La columna vertebral de su dieta". Para legitimar esta opinión buscan una "Consejera de Nutrición"
AVISO 17 Levadura Fleischmann. Revista Semana, Bogotá, Volumen XI - Edición No. 232, julio 7 de 1951

llamada Laura Real que aconseja a las madres sobre la mejor manera de alimentar a sus hijos. A la par de las recomendaciones de consumir una dieta equilibrada, también exalta las cualidades del pan, presentándolo como "base de toda alimentación equilibrada". En la parte inferior se cierra el aviso con la invitación a consumir más pan que termina reforzando el discurso de los avisos.

En el primer aviso aparecen unos niños jugando mientras que en el segundo aviso presenta los seis grupos de alimentos. Las ilustraciones son sencillas, utilizadas como apoyo al mensaje principal. 


\section{Conclusiones $\nabla$}

Los avisos publicitarios analizados responden a un interés de las empresas anunciantes por proyectar su imagen ante la sociedad como compañías respetables, cercanas a la sociedad colombiana. En el caso de Esso su interés es que no sea vista como un monopolio, la imagen que desea proyectar es la de una empresa que tiene un rol fundamental en la sociedad al distribuir "la sangre" que mueve al país y ser un actor de primera línea en la modernización del país, es una imagen que contrasta con la de la compañía, con la que se ha venido enfrentando los sindicalistas sobre todo en los días posteriores al 9 de abril de 1948, donde la refinería de Barrancabermeja fue tomada por los manifestantes durante un lapso prolongado de tiempo.

En el caso de Squibb y Fleischmann pretenden posicionarse en la opinión pública como compañías comprometidas en el esfuerzo por fortalecer las políticas de higiene y salud pública del Estado colombiano. La venta de la levadura o de los medicamentos sería una consecuencia indirecta de estas campañas publicitarias. En estas dos campañas se motiva a que los lectores de los avisos cambien sus hábitos de consumo. El Discurso de los avisos es de carácter terapéutico, detrás de estos mensajes "hay una ideología de una sociedad que atiende a sus miembros como a un enfermo virtual" (Baudrillard, 2007, p 2010).

En lo que concierne a la campaña del Censo hay un claro interés de mostrar a la opinión pública las bondades y beneficios de contar con información estadística actualizada del país, esta tarea es presentada como un esfuerzo patriótico en el que los diferentes actores de la sociedad deben participar para garantizar el éxito. Con los resultados del censo el Estado tendrá las herramientas estadísticas para mejorar la calidad de vida de los colombianos.

Los mensajes e imágenes analizados en su conjunto muestran una imagen idealizada del país en los años cincuenta y las problemáticas se ven como fáciles de resolver con el concurso de la ciencia, la tecnología y la voluntad de la sociedad colombiana. Sin duda en una etapa posterior sería interesante contrastar estas visiones con otras fuentes para ampliar la visión de un periodo interesante en la historia de Colombia. 


\section{Fuentes Primarias}

"Este es nuestro problema", Anunciante: Esso Colombiana S.A. Revista Semana, Bogotá, Volumen X, - Edición No. 226, febrero 17 de 1951.

"Crecimiento del Consumo", Anunciante: Esso Colombiana S.A. Revista Semana, Bogotá, Volumen X - Edición No. 227, febrero 24 de 1951

“Cómo está mejorando la distribución", Anunciante: Esso Colombiana S.A. Revista Semana, Bogotá, Volumen X - Edición No. 228, marzo 3 de 1951

"Un Servicio: No un Monopolio", Anunciante: Esso Colombiana S.A. Revista Semana, Bogotá, Volumen X - Edición No. 229, marzo 10 de 1951

“Entre Confiado.... saldrá satisfecho", Anunciante: Esso Colombiana S.A. Revista Mito, Bogotá, Edición No. 15, agosto - septiembre de 1957

“36 años de gasolina Esso en Colombia", Anunciante: Esso Colombiana S.A. Revista Semana, Bogotá, Volumen XXIII - Edición No. 565, septiembre 27 de 1957

"El Átomo se desintegra", Anunciante: Esso Colombiana S.A. Revista Cromos, Bogotá, Edición No. 2091, junio 17 de 1957

“1951 Censos - Población, Vivienda, Agropecuario", Anunciante: Contraloría General de la República. Revista Semana, Bogotá, Volumen X, edición No. 223, enero 27 de 1951

“El censo de vivienda dará la base para elevar el nivel de vida del pueblo Colombiano", Anunciante: Contraloría General de la República. Revista Semana, Bogotá, Volumen X - Edición No. 223, enero 27 de 1951

"El empadronador voluntario será el soldado del censo continental", Anunciante: Contraloría General de la República. Revista Semana, Bogotá, Volumen X - Edición No. 234, abril 14 de 1951

“Ganaderos: el empadronador necesita saber el número de cabezas de ganado de su hacienda", Anunciante: Contraloría General de la República. Revista Semana, Bogotá, Volumen X - Edición No. 225, febrero 10 de 1951 “¿Cuáles son las ocupaciones predominantes de la población colombiana? Anunciante: Contraloría General de la República. Revista Semana, Bogotá, Volumen X - Volumen X Edición No. 237, mayo 5 de 1951

“La hipertensión arterial no tiene por qué amenazar su futuro", Anunciante: E.R. Squibb \& Sons. Revista Semana, Bogotá, Volumen X - Edición No. 223, enero 27 de 1951

"Una dieta adecuada puede mejorar su apariencia... y su salud", Anunciante: E.R. Squibb \& Sons. Revista Semana, Bogotá, Volumen X - Edición No. 225, febrero 10 de 1951 “ibuenas noticias sobre el cáncer!”, Anunciante: E.R. Squibb \& Sons. Revista Semana, Bogotá, Volumen X - Volumen X - Edición No. 231, marzo 24 de 1951

“La columna vertebral de su dieta..., Anunciante: Levadura Fleischmann. Revista Cromos, Bogotá, Edición No. 2002, abril 4 de 1953

“Su hijo puede estar desnutrido...", Anunciante: Levadura Fleischmann. Revista Semana, Bogotá, Volumen XI - Edición No. 232, julio 7 de 1951

\section{Fuentes Secundarias}

Calvo, Oscar, y Marta Saade. La ciudad en cuarentena. Chicha, patología social y profilaxis. Bogotá: Ministerio de Cultura, 2002.

Noguera, Carlos. "La lucha antialcohólica en Bogotá: de la chicha a la cerveza". En Higienizar, medicar, gobernar. Historia, medicina y sociedad en Colombia, editado por Jorge Valderrama, Álvaro Casas y Eugenia Estrada. Medellín: Universidad Nacional de Colombia, 2004.

Ocampo, José Antonio, y Santiago Montenegro. Crisis mundial, protección e industrialización: Ensayos de historia económica colombiana. Bogotá: Fondo Editorial CEREC, 1984.

Galvis, Silvia, y Alberto Donadío. El jefe supremo: Rojas Pinilla, en la violencia y el poder. Bogotá: Planeta, 1988.

Marulanda Álvarez, Elsy. “Mujeres y violencia, años 50". En Las mujeres en la historia de Colombia, editado por Magdala Velásquez Toro. Bogotá: Norma, 1995, 480-501.

Palacios, Marco, y Frank Safford. Colombia: país fragmentado, sociedad dividida. Bogotá: Norma, 2002.

Bushnell, David. Colombia, una nación a pesar de sí misma. Bogotá: Planeta, 1996.

Baudrillard, Jean. La Sociedad de Consumo, sus Mitos, sus estructuras. Madrid: Siglo XXI , 2007.

Chartier Roger, El mundo como representación. Estudios sobre historia cultural (Barcelona: Gedisa, 2005).

Guarín Martínez, O. (2007). Época de Cambios Radicales. En G. González Uribe, \& A. Mejía, Bogotá, años 50. Bogotá, Colombia: Revista Número Editores. 